\title{
De fiets:
}

Citation for published version (APA):

Oosterhuis, H. (2018). De fiets: Gelijkmaker of distinctiemiddel? AGORA: Magazine voor sociaalruimtelijke vraagstukken, 34(2), 40-43. https://doi.org/10.21825/agora.v34i2.10095

Document status and date:

Published: 01/01/2018

DOI:

10.21825/agora.v34i2.10095

Document Version:

Publisher's PDF, also known as Version of record

\section{Document license:}

Taverne

\section{Please check the document version of this publication:}

- A submitted manuscript is the version of the article upon submission and before peer-review. There can be important differences between the submitted version and the official published version of record.

People interested in the research are advised to contact the author for the final version of the publication, or visit the DOI to the publisher's website.

- The final author version and the galley proof are versions of the publication after peer review.

- The final published version features the final layout of the paper including the volume, issue and page numbers.

Link to publication

\footnotetext{
General rights rights.

- You may freely distribute the URL identifying the publication in the public portal. please follow below link for the End User Agreement:

www.umlib.nl/taverne-license

Take down policy

If you believe that this document breaches copyright please contact us at:

repository@maastrichtuniversity.nl

providing details and we will investigate your claim.
}

Copyright and moral rights for the publications made accessible in the public portal are retained by the authors and/or other copyright owners and it is a condition of accessing publications that users recognise and abide by the legal requirements associated with these

- Users may download and print one copy of any publication from the public portal for the purpose of private study or research.

- You may not further distribute the material or use it for any profit-making activity or commercial gain

If the publication is distributed under the terms of Article $25 \mathrm{fa}$ of the Dutch Copyright Act, indicated by the "Taverne" license above, 


\section{ESSAY - Harry Oosterhuis}

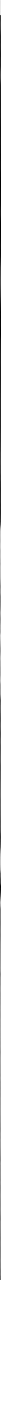

In Nederland fietst vrijwel iedereen: jong en oud, man en vrouw, hoog en laag, en arm en rijk. Maar deze egalitaire fietscultuur is uitzonderlijk. Dat fietsen elders niet vanzelfsprekend is, hangt deels samen met stand en status. In Amerika is een discussie ontbrand over sociale rechtvaardigheid in het fietsbeleid.

In een groot deel van de Westerse wereld bestaat tegenwoordig overeenstemming over het nut van de fiets als dagelijks vervoermiddel, ook al betekent dit niet dat het aandeel van de fiets in het verkeer overal, zoals in Zuid- en Oost-Europa, spectaculair is toegenomen. De meest genoemde argumenten hebben te maken met efficiëntie (de snelheid en flexibiliteit op de korte afstand), duurzaamheid en gezondheid. Daarnaast worden de sociale voordelen van fietsen aangeprezen. Het zou de anonimiteit van de publieke ruimte en de fragmentatie van de gebouwde omgeving tegengaan en zo de leefbaarheid van steden bevorderen. Bovendien zou het rijwiel, betaalbaar en toegankelijk voor vrijwel iedereen met een redelijke conditie, de mobiliteit en maatschappelijke kansen van achtergestelde personen kunnen vergroten. Fietsactivisten, onderzoekers en beleidsmakers veronderstellen dat fietsen goed is voor iedereen, ongeacht sociale klasse, culturele achtergrond of persoonlijke capaciteiten. Het wordt overwegend begrepen in termen van een eigen keuze, die zou zijn te beïnvloeden door voorlichting, een adequate ruimtelijke ordening en een geschikte verkeersinfrastructuur. De meeste planologen, vervoersdeskundigen, beleidsonderzoekers en fietsactivisten vertrouwen op de effectiviteit van een professionele aanpak: vakkundig lobbywerk, wetenschappelijke onderbouwing met statistische gegevens, nauwgezette beleidsvorming en technische interventies.
In Amerika stellen kritische en politiek-geëngageerde fietsonderzoekers deze benadering nu ter discussie. Die discussie lijkt zuiver instrumenteel en politiek neutraal, maar is dat volgens hen allesbehalve. Door de eenzijdige nadruk op het belang van infrastructurele faciliteiten blijft de vraag wie daar wel en niet gebruik van (kunnen) maken, onbeantwoord. De mogelijkheden en middelen om te fietsen zijn niet gelijk verdeeld, en er is te weinig aandacht voor economische belangen, sociale diversiteit, culturele gevoeligheden en specifieke behoeften van achtergestelde groepen. Een met publieke middelen gefinancierd fietsbeleid dat voornamelijk is toegesneden op de behoeften van de blanke middenklasse en nauwelijks tegemoet komt aan de belangen en ervaringen van kansarmen, voldoet niet aan de eis van de verdelende rechtvaardigheid. Fietsbeleid zou pas rechtvaardig zijn als het ook de mobiliteitskansen van achterblijvers vergroot en hun maatschappelijke participatie en ontplooiing ondersteunt. Op basis van een sociaal- en cultuurwetenschappelijke benadering en participerende en etnografische onderzoekmethoden pleiten een aantal jonge onderzoekers voor fietsactivisme dat aansluit bij de strijd voor burgerrechten en emancipatie. Hun invalshoek heeft inmiddels tal van studies opgeleverd. 


\section{Gentrificatie en cycle chic}

De zogenaamde equity turn in het fietsonderzoek is aangewakkerd door protesten uit Afro- en Latijns-Amerikaanse gemeenschappen in diverse Amerikaanse steden tegen de aanleg van rijwielvoorzieningen in hun woonbuurten. Het ongenoegen was niet gericht tegen fietsen of fietspaden op zichzelf, maar wel tegen het bredere beleid waarvan de nieuwe fietsinfrastructuur deel uitmaakt: het streven om deze buurten aantrekkelijk en 'leefbaar' te maken voor hoogopgeleide professionals in de kenniseconomie en creatieve sector. Terwijl de tweewieler in autoland Amerika als dagelijks vervoermiddel uit de gratie was geraakt en van lieverlee met sport, recreatie, studenten en kinderspel werd geassocieerd, heeft de zogenaamde creatieve klasse de fiets een nieuwe status gegeven als onderdeel van een trendy consumptiepatroon en kosmopolitische leefstijl. Met een aanbod aan mooi vormgegeven, technisch geavanceerde en prijzige (retro)rijwielen spelen de fietsindustrie en -handel op deze cycle chic mode in. Stadsbesturen zijn doordrongen geraakt van het economische potentieel van een fietsvriendelijke omgeving: zij investeren in fietsfaciliteiten om hun stad aantrekkelijk te maken voor de creatieve klasse. Ook hebben deze een plaats gekregen in de marketing van toeristensteden. Woordvoerders van de belangrijkste federale fietsorganisatie in de Verenigde Staten, de League of American Bicyclists, benadrukken dat dergelijke investeringen in menig opzicht lucratief zijn: niet alleen dalende kosten voor gezondheidszorg, maar ook stijgende werkgelegenheid, omzet in winkelstraten, onroerendgoedprijzen, investeringen en dito belastinginkomsten voor steden. Onder invloed van neoliberaal beleid staat fietspromotie niet alleen in dienst van doeleinden als duurzaamheid en welzijn, maar ook van economisch gewin. Daardoor is de sociaal-culturele en maatschappijkritische dimensie van het fietsactivisme van de agenda verdrongen en blijft de structurele dominantie van het autoverkeer buiten schot.

Terwijl in de media en onder veel fietsonderzoekers sprake is van een hoopvolle 'fietsrenaissance', heeft de oprukkende cycle chic in enkele Amerikaanse steden weerzin en verzet opgeroepen onder kansarme groepen. Zij zien het groeiende fietsenthousiasme als een zoveelste symptoom van gentrificatie, dat wil zeggen stijgende woonlasten, opgeschroefde woonnormen, een exclusief horecaen winkelaanbod, en een opgedofte, deels geprivatiseerde en gesurveilleerde publieke ruimte waarin zij zich niet welkom voelen. Voor de oorspronkelijke buurtbewoners zijn fietsende yuppen en hipsters een teken dat de blanke middenklasse hun woonbuurten koloniseert en hen naar de periferie verdrijft. Hun dagelijks af te leggen woon-werk afstanden nemen toe, terwijl het openbaar vervoer en de fietsopties in de buitenwijken te wensen overlaten. Voor zover ze zelf van de tweewieler gebruik maken, meestal uit noodzaak omdat ze zich geen gemotoriseerd vervoer kunnen veroorloven, hebben zij weinig aan de nieuwe fietsvoorzieningen. Die zijn niet gelijkmatig over de stad verdeeld, maar doorgaans geconcentreerd in het centrum en de aanpalende buurten, en daardoor overwegend toegesneden op de woon- en werkplekken en mobiliteitspatronen van de beter gesitueerden. Op deze manier is fietsinfrastructuur geen politiek-neutrale voorziening maar een weerspiegeling van sociale en etnische ongelijkheid. Een en ander heeft inmiddels politieke gevolgen gehad. Enkele jaren geleden, bijvoorbeeld, verloor een zwarte burgemeester van Washington DC door zijn inzet voor de aanleg van fietspaden de steun van een groot deel van zijn achterban, waardoor hij niet werd herkozen.

\section{Keuzefietsers en fietsers uit noodzaak}

De technocratische aanpak van fietslobbyisten en beleidsmakers is vooral geënt op de aspiraties en leefstijl van bevoorrechte middenklassers, voor wie wielrijden een bewuste en positieve, deels ook vooruitstrevende politieke keuze is. Desgewenst kunnen deze choice riders (keuzefietsers) naar behoefte ook beschikken over andere vervoersmiddelen. Fietsers uit de laagste inkomensgroepen, in Amerika voor een groot deel met een etnische of migratie-achtergrond, zijn daarentegen uit economische noodzaak en vaak door het gebrek aan een geldig rijbewijs of vanwege hun illegale status op de tweewieler aangewezen. Deze captive riders (fietsers uit noodzaak) hebben geen alternatief en hun rijwielgebruik berust niet op eigen voorkeur. Voor hen is het geen verrijkende ervaring of ideologische keuze, laat staan hip en cool of conspicuous consumption, maar een onvermijdelijk bestanddeel van hun armoede en lage sociale status. Zij kunnen zich niet voorstellen dat mensen die zich een auto kunnen veroorloven, kiezen voor fietsen.

Op geen enkele manier voelen deze captive riders zich betrokken bij de fietsbeweging en het beleid, en omgekeerd vallen ze nagenoeg buiten het blikveld van professionele onderzoekers, activisten, lobbyisten en besluitvormers. Dit is des te opmerkelijker aangezien statistieken aangeven dat deze wielrijders in het dagelijkse verkeer in feite talrijker zijn dan de keuzefietsers. Hun fietsgewoonten zijn ingegeven door praktische noodzaak en kenmerken zich door ongeregelde en improvisorische muddling through, het vindingrijke en deels illegale gebruik van sluipwegen en ongebruikelijke routes buiten de reguliere verkeers- en fietsinfrastructuur om. Beleidsvormers en fietsactivisten zouden hier veel van kunnen leren, maar de gevestigde fietsbeweging en de meeste fietsers uit de middenklasse moeten niets hebben van dergelijke ongeregelde do-it-yourself praktijken. Ze vrezen voor een nog slechter publiek imago van hun vervoerswijze, dat overheden en het brede publiek toch al niet serieus nemen.

De blindheid voor de rommelige fietspraktijken is ook te wijten aan de selectiviteit van de empirische gegevens in het sociaalwetenschappelijke beleidsonderzoek. Tellingen van vervoersbewegingen vinden hoofdzakelijk plaats op routes met veel fietsende blanke middenklassers wanneer zij in groten getale onderweg zijn, zoals het begin en einde van de reguliere kantoordag. Enquêtes bereiken doorgaans hoofdzakelijk gemotiveerde keuzefietsers voor wie de vragen herkenbaar en relevant zijn, en die hun mening kunnen en willen ventileren. Zulk zelfselectief onderzoek gaat voorbij aan de noden en ervaringen van de achtergestelde fietsers en wekt mogelijk hun wantrouwen op. Hun fietsbeleving is nauw verbonden met hun dagelijkse strijd om het bestaan, waarin basisbehoeften als werk, inkomen, gezondheid en huisvesting voorop staan. Vanwege hun onregelmatige werk fietsen ze bijvoorbeeld vroeg of laat op de dag, buiten de reguliere spitsuren, en hun woon- en werkplekken zijn vaak niet aangesloten op de fietsinfrastructuur. Daarbij is de verkeersveiligheid in het geding: etnische minderheden zijn oververtegenwoordigd onder de fietsverkeersslachtoffers in Amerika. Volgens de kritische fietsonderzoekers hangt dat deels samen met de raciale vooroordelen van roekeloos rijdende blanke automobilisten - een oordeel dat moeilijk is te staven. Waarschijnlijk speelt ook mee dat captive riders geen andere keus hebben dan gebruik te maken van reguliere verkeerswegen. Daarnaast hebben de machtsverhoudingen in de publieke ruimte en raciale vooroordelen gevolgen voor de sociale veiligheid van achtergestelde fietsers. In Amerika zien velen fietsen sowieso al als buitenissig en als het rijgedrag van deze fietsers dan ook nog rommelig is en hun etnische achtergrond al gauw met illegale activiteiten wordt geassocieerd, dan vallen zij extra op en worden zij doelwit van politiecontroles. Vooral jonge Afro-Amerikaanse mannen en vaak illegaal verblijvende gastarbeiders hebben in dit verband reden om te vrezen voor discriminatie. Ook ervaren zij fietsdiefstal als een groot risico, temeer vanwege hun totale afhankelijkheid van dit vervoermiddel en hun beperkte middelen om een gestolen exemplaar te vervangen.

\section{Menselijke infrastructuur}

De Amerikaanse fietsonderzoekers en -activisten die zich op sociale ongelijkheid en rechtvaardigheid richten, laten het niet bij 


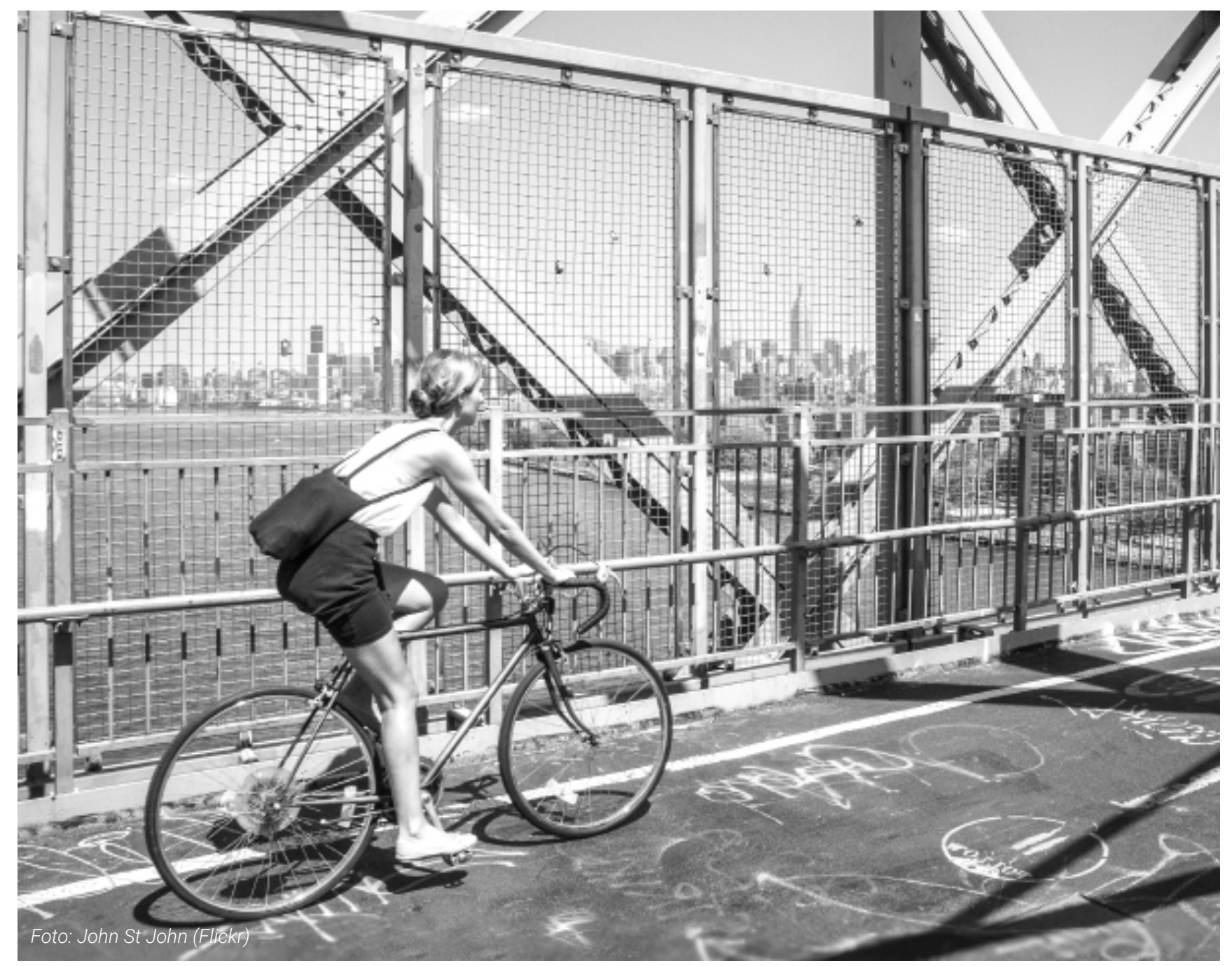

een kritische analyse van het gangbare, in hun ogen exclusieve en dirigistische fietsbeleid. Aan de hand van concrete praktijken en projecten, vooral in enkele Amerikaanse steden, maar ook in Latijns-Amerika en Europa, wijzen zij op mogelijkheden voor meer sociaal rechtvaardig fietsactivisme op basis van 'menselijke infrastructuur'. Door fietspromotie te verbinden met emancipatiebewegingen, maatschappelijk werk, buurtactivisme, do-it-yourself projecten zoals collectieve reparatiewerkplaatsen, wielermanifestaties en massale demonstratieve tochten door verschillende buurten in steden zouden achtergestelde groepen beter worden bereikt en aangemoedigd. Wat die uiteenlopende voorbeelden gemeen hebben is het idee dat fietsen meer is dan een vervoerswijze waarvoor individuen op basis van praktische redenen en persoonlijke voorkeuren kiezen. Het zou ook de kwaliteit van de samenleving kunnen verbeteren en sociale en etnische kloven kunnen overbruggen. Veel auteurs die over sociaal rechtvaardig fietsactivisme schrijven, participeren in deze nieuwe beweging en overschrijden de grens tussen wetenschappelijke afstand en maatschappelijke betrokkenheid. Enkelen van hen geven als fietsactivist zelf mee vorm aan de praktijken die zij onderzoeken. Dat hoeft op zichzelf niet bezwaarlijk te zijn zo lang de etnografische onderzoeker in staat is tot kritische zelfreflectie op zo'n dubbelrol, daar rekenschap over aflegt en een evenwicht weet te bewaren tussen engagement en analyse.

Jammer genoeg brengen hun verontwaardiging en activisme met zich mee dat zij zich nogal eens verliezen in politiek wensdenken, zelfingenomenheid en een politiek correcte en zelfs propagandistische toon, terwijl de concrete resultaten van allerlei nieuwe initiatieven en projecten, die het fietsen onder achtergestelde groepen moeten bevorderen, in de lucht blijven hangen. Ook is het de vraag of het optimisme dat sommigen aan de dag leggen over de mogelijkheden om het fietsbeleid in Amerika om te buigen in de richting van sociale rechtvaardigheid, terecht is. Het vaak aangehaalde voorbeeld van het voor Amerikaanse begrippen succesvolle, maar tegelijkertijd omstreden fietsbeleid in Portland (Oregon) geeft te denken. Toen er enkele jaren geleden in deze stad vanuit de Afro-Amerikaanse gemeenschap verzet ontstond tegen de aanleg van fietspaden in hun eerder verwaarloosde buurt, ontstond er een verhitte discussie over deze zogenoemde white bikelanes of gentrification. De bewoners voelden zich gepasseerd en miskend. Hun klachten over verkeersoverlast en -onveiligheid waren jarenlang genegeerd en nu kregen yuppen het opeens gedaan dat er in een rap tempo fietspaden werden aangelegd waar de eersten niet om hadden gevraagd. De protesten leidden ertoe dat de beleidsmakers de discussie moesten aangaan met de bewoners en dat de plannen werden aangepast om tegemoet te komen aan hun ongenoegen. Maar het bleef bij materiële aanpassingen. Het begrip voor dergelijke gevoeligheden, die waren geworteld in raciale achterstelling, betekende allerminst dat er iets werd gedaan aan de structurele sociaaleconomische gevolgen van de gentrificatie.

Verder is het twijfelachtig of fietsers uit noodzaak te winnen zijn voor de idealen van de jonge, hoog opgeleide activisten annex wetenschappers. Voor achtergestelde groepen blijft fietsen een vervoerswijze uit nood die zij het liefst zo snel mogelijk willen inwisselen voor de auto. Autorijden behoort tot de kern van de Amerikaanse droom. Het is in de Amerikaanse samenleving bij uitstek een teken van succesvolle integratie en het blijkt dat immigranten meer autorijden naarmate zij langer in de Verenigde Staten verblijven. 
Wat de sociaal-kritische fietsonderzoekers delen met de gevestigde fietslobby en beleidsmakers is het toch wel wat naïeve geloof in de politieke maakbaarheid van het fietsen, ook al verschillen de meningen over de wijze waarop - door middel van materiële of menselijke infrastructuur. Ook onderschatten de meeste Amerikaanse fietsonderzoekers de taaiheid van historisch gegroeide fietspatronen en hebben ze weinig oog voor internationale verschillen. Zij lijken zich er nauwelijks van bewust dat de discussie over een sociaal rechtvaardig fietsbeleid grotendeels typisch Amerikaans is en voortkomt uit de specifieke Angelsaksische geschiedenis van het fietsen, waarin het een buitengewoon vervoermiddel voor specifieke groepen, bijzondere omstandigheden en een bepaalde levensfase (bijvoorbeeld de studietijd) is geworden. Al veel eerder, in het interbellum en vooral na de Tweede Wereldoorlog, en veel ingrijpender dan in Europa, is de fiets als verkeersmiddel in de Verenigde Staten gemarginaliseerd als armzalig voertuig voor losers die zich geen auto kunnen veroorloven. Aan de andere kant is dit verfoeide vehikel in de laatste twee decennia opgewaardeerd als distinctiemiddel van hoogopgeleiden, yuppies, hipsters en sportievelingen. Fietsen blijft zo nauw verbonden met (lage dan wel hoge) sociale status en uitzonderlijke leefstijl, beeldvorming die nog eens wordt uitvergroot door schrille sociale en raciale tegenstellingen en politiek-culturele polarisatie.

\section{Voor achtergestelde groepen blijft fietsen een vervoerswijze uit nood}

\footnotetext{
Linksdraaiende yuppen en vegetariërs

Dergelijke tendensen ontbreken evenmin in grote Europese steden. Ook hier bevorderen gentrificatie en toerisme het aanzien van fietsen - waarbij niet vergeten moet worden dat het utilitaire gebruik van de tweewieler op het platteland en suburbane gebieden een dalende tendens vertoont. Amsterdam en Londen zijn tegenpolen wat betreft het aandeel van fietsers in het verkeer. Maar voor beide steden geldt dat hoogopgeleiden oververtegenwoordigd en laagopgeleiden en allochtonen van niet-Westerse afkomst ondervertegenwoordigd zijn; de laatste groep geeft de voorkeur aan de auto, de scooter of het openbaar vervoer. Het is tekenend dat een vastgoedontwikkelaar die op het Amsterdamse Zeeburgereiland een prestigieuze woonwijk wil bouwen, onlangs van de gemeente een fietsbrug eiste ten behoeve van een goede centrumverbinding met het eiland. Projectontwikkelaars als pleitbezorgers van fietsinfrastructuur; dat was nog niet zo lang geleden zelfs in fietsland Nederland moeilijk voorstelbaar.

Tegelijkertijd klinkt net als in Amerika ook in Europa af en toe ongenoegen over bevoorrechte en arrogante fietsers die te veel ruimte zouden opeisen. In Parijs bijvoorbeeld is er ongezouten kritiek op de ambitie van het stadsbestuur om 'een wereldhoofdstad van het fietsen' te worden. Tegenstanders beweren dat bevlogen bestuurders een ideologische 'oorlog tegen de auto' voeren om 'linksdraaiende yuppen' en bobo's (bourgeoisbohème) te plezieren, terwijl hardwerkende automobilisten langer in de file staan en nauwelijks meer een betaalbare parkeerplaats kunnen vinden. Een soortgelijk geluid kwam onlangs uit Polen, waar een conservatief-nationalistische minister opmerkte dat 'een liberale wereld van fietsers en vegetariërs' wezensvreemd is aan 'traditionele Poolse waarden'. In dit verband is het de vraag welke uitwerking het populisme op het imago van de tweewieler en het fietsbeleid heeft.
}

Toch zijn de tweewieler en het fietsbeleid in ons land, in tegenstelling tot Amerika en ook in andere Europese landen, nauwelijks onderwerp van politiek-ideologische strijd. Ook spelen zij nauwelijks een rol in discussies over de sociaaleconomische en culturele achtergrond en gevolgen van de ook in Nederlandse steden oprukkende gentrificatie. In studies daarover krijgen factoren als de kunstscene, seksuele diversiteit en de kwaliteit van het culinaire aanbod ruim aandacht, maar ontbreekt de fiets, terwijl die voor de Amerikaanse stadssocioloog Florida juist wel een belangrijk kenmerk van de creatieve klasse en gentrificatie is. Dat komt grotendeels doordat de Nederlandse fietscultuur zich met de Deense al sinds jaar en dag in de Westerse wereld niet alleen onderscheidt met de hoogste fietsdichtheid en de beste infrastructuur, maar zich ook kenmerkt door een egalitair ethos. Toen arbeiders vanaf de Eerste Wereldoorlog massaal de beschikking over fietsen kregen, was dat voor de burgerij geen reden, zoals elders wel, voor een afwaardering van het voertuig als arbeideristisch, armoedig en achterhaald. In Nederland geldt het rijwiel nog steeds als een geëigend vervoermiddel voor alle bevolkingsgroepen. In veel grotere mate dan in andere landen, vooral in de Angelsaksische wereld, vormen fietsers hier een doorsnee van de gehele bevolking, afgezien van bevolkingsgroepen met een niet-Westerse achtergrond. Voor migranten is leren fietsen vaak een onderdeel van hun integratietraject en voor de vrouwen onder hen ook vaak een in eigen kring omstreden middel tot grotere zelfstandigheid. Voor mannen van niet-Westerse afkomst verleent de fiets over het algemeen nog altijd minder aanzien dan de auto of scooter. Verder spelen sociale en etnische spanningen en statusgevoeligheid, die het fietsbeleid in veel andere landen politiseren en belemmeren, op dit terrein in Nederland nagenoeg geen rol. Publieke middelen voor rijwielfaciliteiten worden op pragmatische wijze verdeeld en deze voorzieningen zijn in principe voor iedereen toegankelijk. Dit alles verklaart dat sociale rechtvaardigheid hier in tegenstelling tot de Verenigde Staten en ook andere Angelsaksische landen in het fietsbeleid nauwelijks een punt van discussie is en het vermoedelijk ook niet zal worden.

\section{Literatuurselectie \\ Florida, R. (2017) The new urban crisis. How our cities are increasing \\ inequality, segregation, and failing the middle class - and what we can do about it. New York: Basic Books, 2002 \\ Golub, A., M.L. Hoffmann, A.E. Lugo en G.F. Sandoval (Eds. 2016) Bicycle justice and urban transformation: Biking for all? Londen: Routledge. Hoffmann, M.L. (2016) Bike lanes are white lanes: Bicycle advocacy and urban planning. Londen: University of Nebraska Press. \\ Lugo, A.E. (2013) Body-City-Machine: Human Infrastructure for Bicycling in Los Angeles. Proefschrift, Department of Anthropology, University of California, Irvine, CA \\ Stehlin, J. (2015) Cycles of investment: bicycle infrastructure, gentrification, and the restructuring of the San Francisco Bay Area. Environment and Planning, A 47, 121-137.}

Harry Oosterhuis (harry.oosterhuis@maastrichtuniversity.nl) is als historicus verbonden aan de Faculteit der Cultuur en Maatschappijwetenschappen van de Universiteit Maastricht. 